\title{
Und, was machen Sie so?
}

_ Es ist schon eine Weile her, da fuhr ich mit der Mitfahrgelegenheit nach Stuttgart. Den Fahrer kannte ich nicht, ein junger Typ mit kurzen, dunklen Haaren, und ich als Beifahrerin. Das bin ich übrigens gerne. Da hat man Beinfreiheit, und manchmal darf man sogar am Radio drehen.

_ Mein Fahrer und ich hörten Musik oder unterhielten uns, übers Autofahren, das Reisen und das Wetter. Irgendwann - man kommt ja nie drum herum die Frage: „Und, was machst du so?“ Ich bin ja mittlerweile in dem Dilemma, zwei Berufe mit mir herumzutragen: Ergotherapeutin und Redakteurin. Und, nein - „Redakteurin“ lässt sich nicht leichter erklären. Ich weiß das jetzt. Auch da schiebt jeder gleich als Zweites hinterher: „Was macht man denn da?" Erklären muss man also immer.

_ Ich antwortete: „Ergotherapeutin“, und wollte ihm erzählen, was Ergotherapeuten alles können. Da kam sein „Ah ja. Kenn ich“. Ihm war mal eine Sehne gerissen, und er erhielt Ergotherapie. Jetzt plauderte er detailliert über Sehnen und Handtherapie. Ich hatte nicht erzählt, dass ich in der Psychiatrie tätig war und seit der Ausbildung mit Sehnen wenig zu tun hatte. Ich war überfordert. Er wusste zu viel! Und nicht nur das: Ich war noch nicht einmal die erste Ergotherapeutin, die in sein Auto gestiegen ist!

_ Mir sind weitere Menschen begegnet, die nichts über Ergotherapie wissen wollten, einfach weil sie den Beruf schon kennen. Und tatsächlich - die Ergos machen sich breit in Deutschland: Neulich sah ich im Fernsehen eine Ergotherapeutin beim „Perfekten Dinner“ kochen. Andere geben Experteninterviews in regionalen Zeitungen oder in Focus-Schule. Das imponiert mir: Ergotherapeuten sind präsent, und sie präsentieren sich gut.

_ Vielleicht sollten sich Ergotherapeuten darauf einstellen, dass sie ihren Beruf nicht mehr so oft erklären brauchen. Vielleicht bricht eine Zeit an, in der wir uns freuen, wenn wir wieder erklären dürfen... Ich warte einfach mal ab.

Ihre

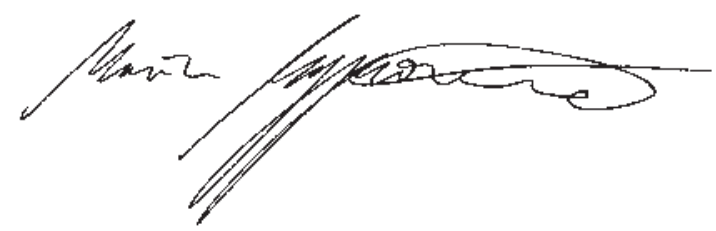

ZU GEWINNEN

Kursplatz

1 Kurs „Update Armrehabilitation“

Seite 46

Bücher

3-mal

„Gute Nacht, bis morgen“ Seite 27

3-mal „Leitfaden

Versicherungen“"

Seite 36

Und außerdem...

1 Tragetuch

Seite 17

1 Bauch-

und Rückentrage

Seite 17 